\title{
A Sensitive New Assay System for Serum Wisteria floribunda Agglutinin-reactive Ceruloplasmin that Distinguishes Ovarian Clear Cell Carcinoma from Endometrioma
}

Maki Sogabe ${ }^{1}$, Shun Kojima ${ }^{2}$, Takatoshi Kaya ${ }^{2}$, Azusa Tomioka ${ }^{1}$, Hiroyuki Kaji ${ }^{1}$, Takashi Sato ${ }^{1}$, Yasunori Chiba ${ }^{1}$, Akira Shimizuํㅜ, Nana Tanaka' ${ }^{1}$, Nao Suzuki ${ }^{3}$, Io Hayashi ${ }^{4}$, Mikio Mikami ${ }^{4}$, Akira Togayachi ${ }^{*}{ }^{*}$, and Hisashi Narimatsu ${ }^{1 *}$.

${ }^{1}$ Cellular and Molecular Biotechnology Research Institute, National Institute of Advanced Industrial Science and Technology, Central-5, 1-1-1 Higashi, Tsukuba, Ibaraki, 305-8565, Japan; ${ }^{2}$ Konica Minolta, Inc., No. 1 Sakura-machi, Hino, Tokyo, 191-8511, Japan; ${ }^{3}$ Department of Obstetrics and Gynecology, St. Marianna University of Medicine, 2-16-1 Sugao, Miyamae-ku, Kawasaki, Kanagawa, 216-8511, Japan; ${ }^{4}$ Department of Obstetrics and Gynecology, Tokai University, 143 Shimokasuya, Isehara, Kanagawa, 259-1193, Japan.
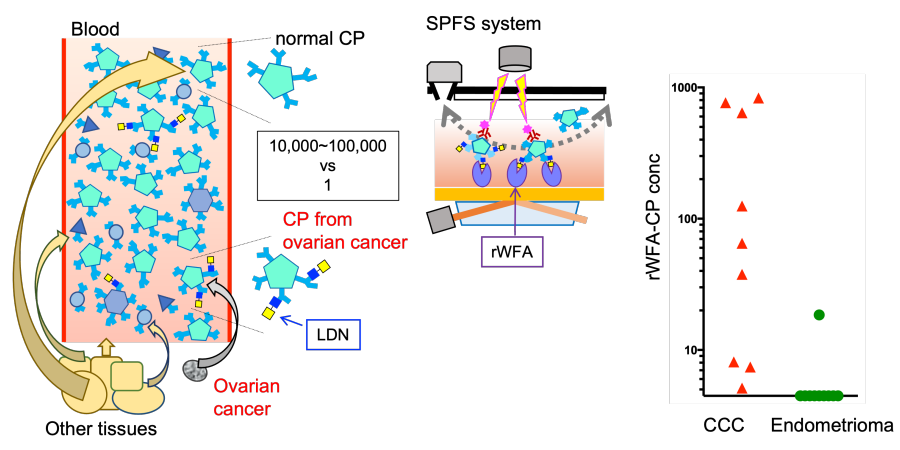


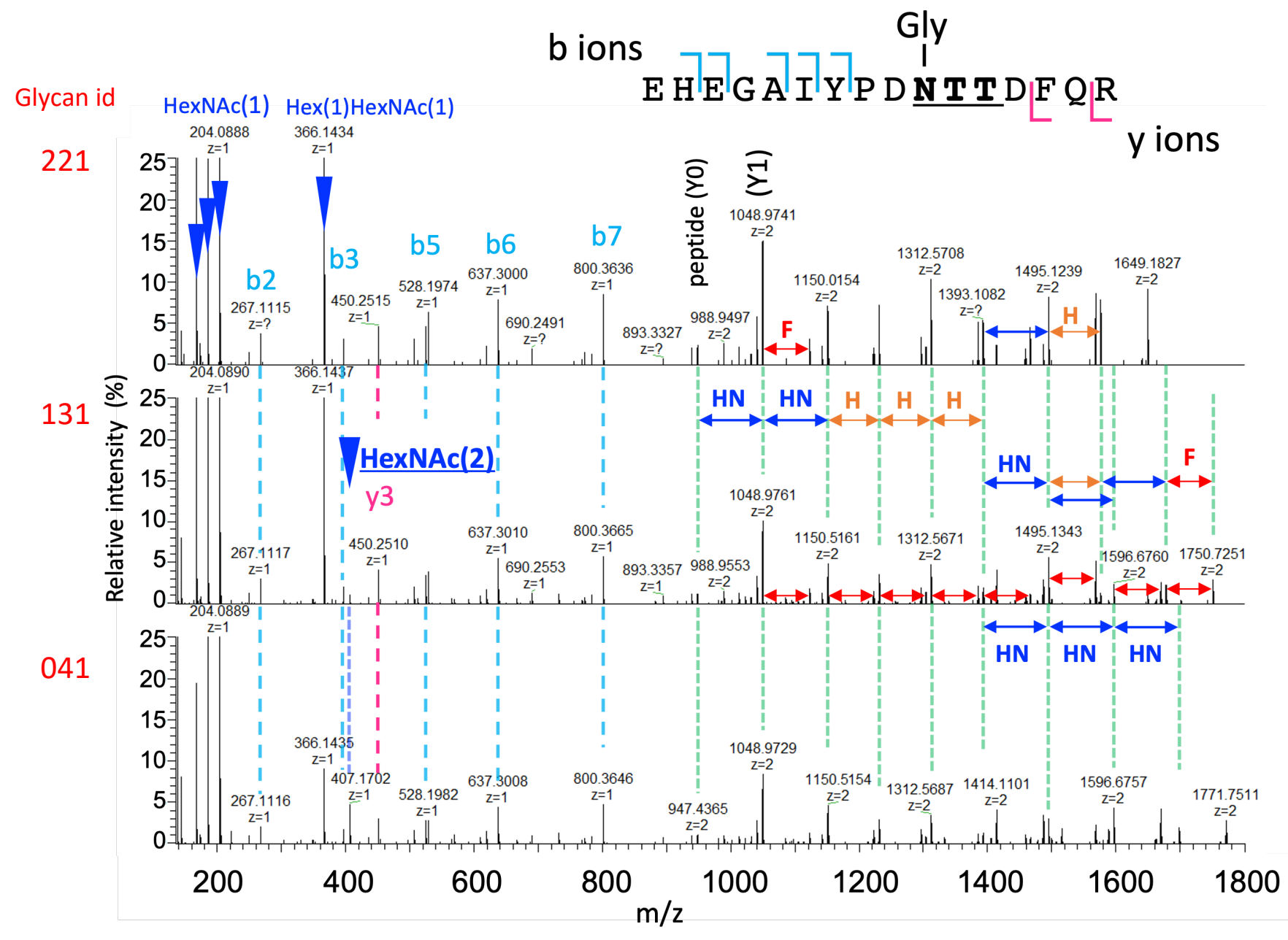

Supplemental Figure 1. HCD MS2 spectra of glycopeptides including Asn-138 of ceruloplasmin (CP) expressed by HEK293 (rCP). Signals shown with blue arrowheads were assigned as glycan diagnostic ions. Glycan fragment of $\mathrm{m} / \mathrm{z} 407.17$ indicates the presence of HexNAc(2) motif (underlined) suggesting GalNAc $\beta 1,4 G$ IcNAc (LDN) on the glycan. Pale blue and pink dotted lines present the $b$ and $y$ ions, respectively. Green dotted lines show signals of peptide and that having glycan portion. Glycan id 131 have both $\mathrm{H}(\mathrm{Hex})+\mathrm{HN}$ (HexNAc) and $\mathrm{HN}^{*} 2$ fragments suggesting Gal $\beta 1,4 \mathrm{GlcNAc}$ (LacNAc) and LDN are seemed on the tri-mannosyl core. 

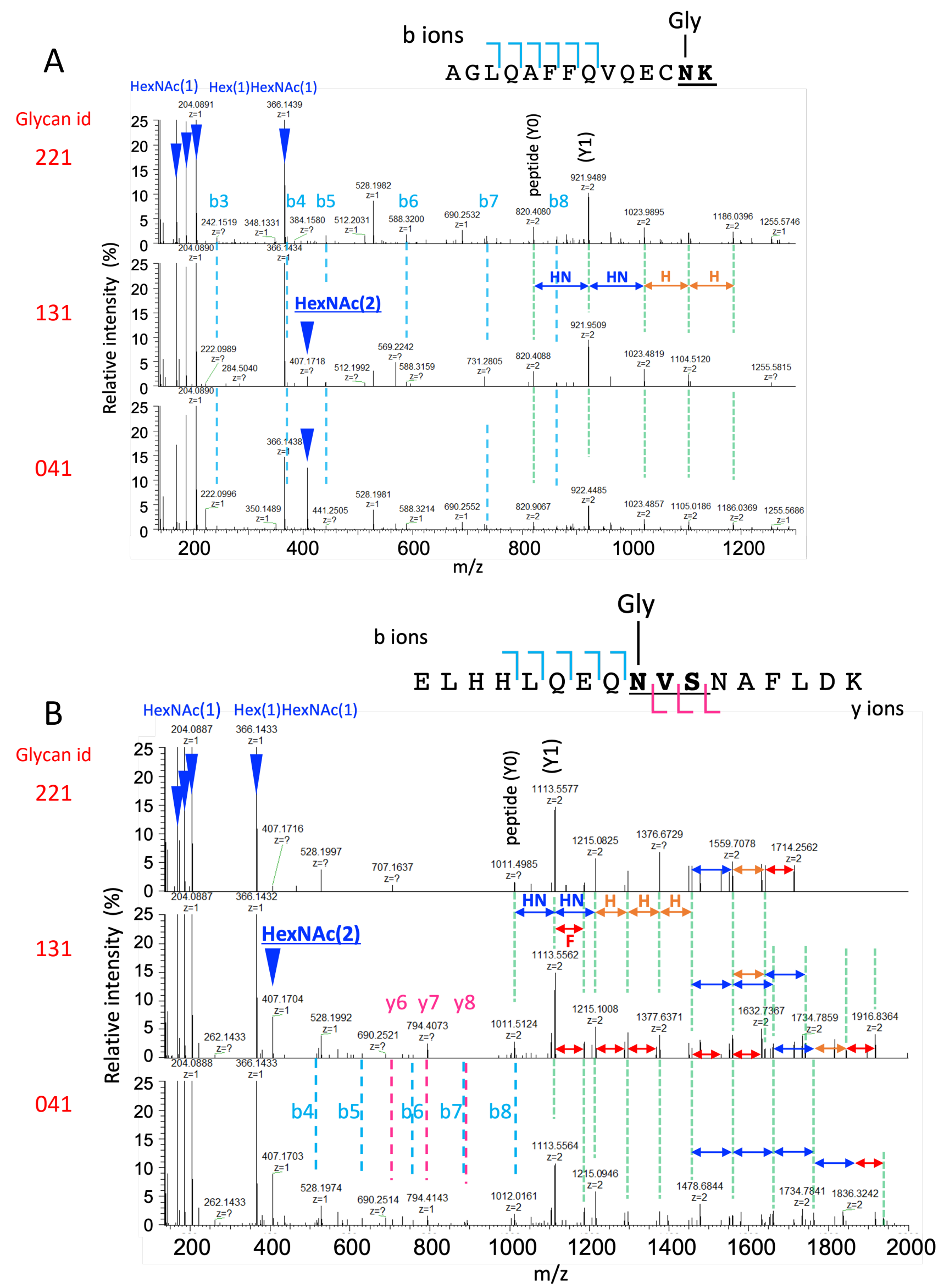

Supplemental Figure 2. HCD MS2 spectra of ceruloplasmin (CP) expressed by HEK293 (rCP). A) Glycopeptides including Asn-358 and B) glycopeptides including Asn-762. Signals shown with blue arrowheads were assigned as glycan diagnostic ions. Glycan fragment of $\mathrm{m} / \mathrm{z} 407.17$ indicates the presence of $\operatorname{HexNAc}(2)$ motif (underlined) suggesting GaINAc $\beta 1,4 G I c N A c$ (LDN) on the glycan. Pale blue and pink dotted lines present the $b$ and $y$ ions, respectively. Green dotted lines show signals of peptide and that having glycan portion. Glycan id 131 have both $\mathrm{H}$ (Hex) + HN (HexNAc) and HN*2 fragments suggesting Gal $\beta 1,4 G I c N A c$ (LacNAc) and LDN are seemed on the tri-mannosyl core. 


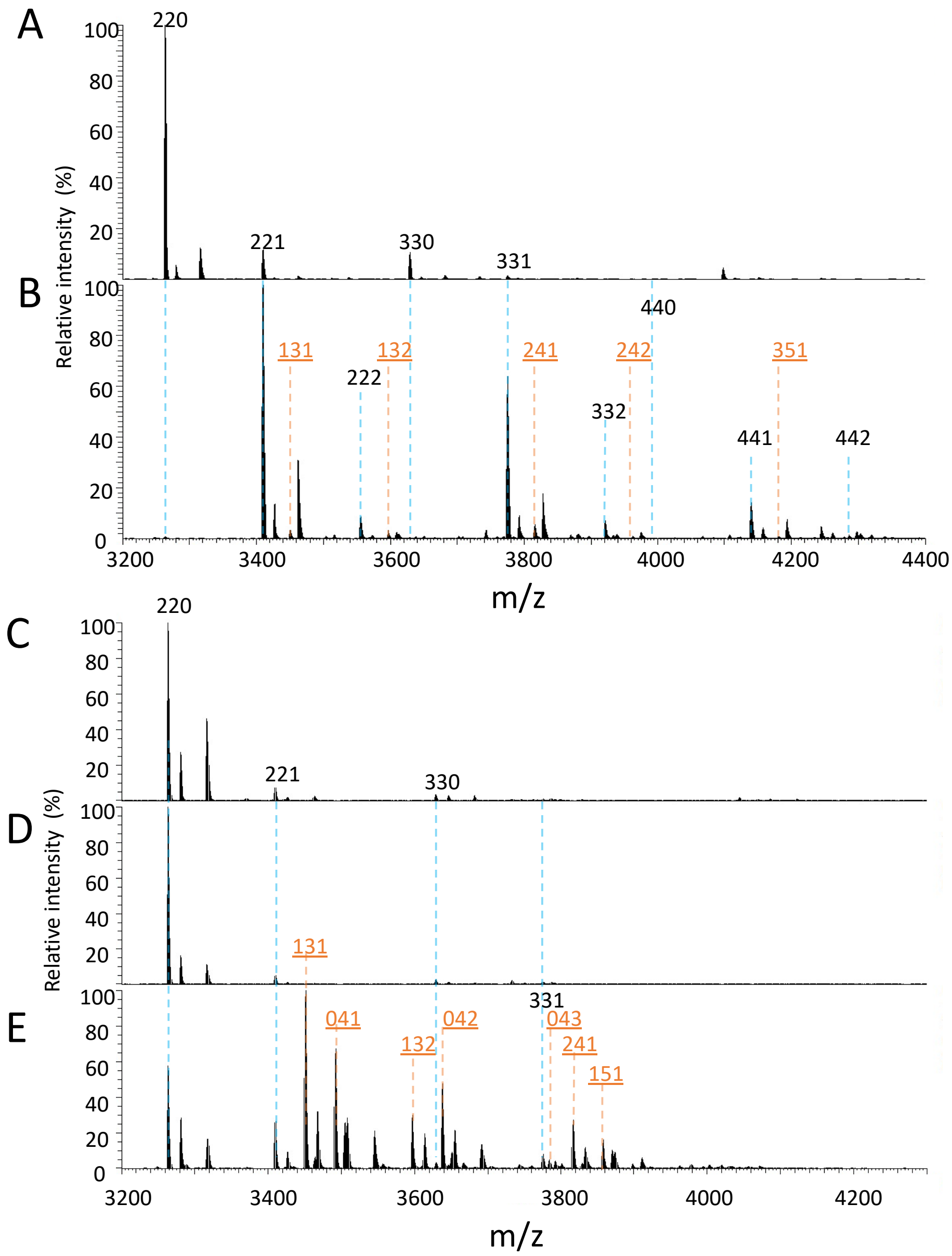

Supplemental Figure 3. Comparison of glycan composition on Asn-358 of CP. (A) Normal human plasma, (B) RMG-V cell line culture supernatant, and (C-E) ascites of CCC patients, specifically (C) nonfractionated, (D) nWFA-pass, and (E) nWFA-bound fractions. The numbers indicate signal ids (XYZ), with each digit presenting glycan compositions, which represent the numbers of $\operatorname{Hex}(X)$, HexNAc $(Y)$, and dHex (Z) monosaccharides, respectively, on the trimannosyl core (Hex3HexNAc2). Signal ids of putative LDN-containing glycan compositions are in orange and underlined. 


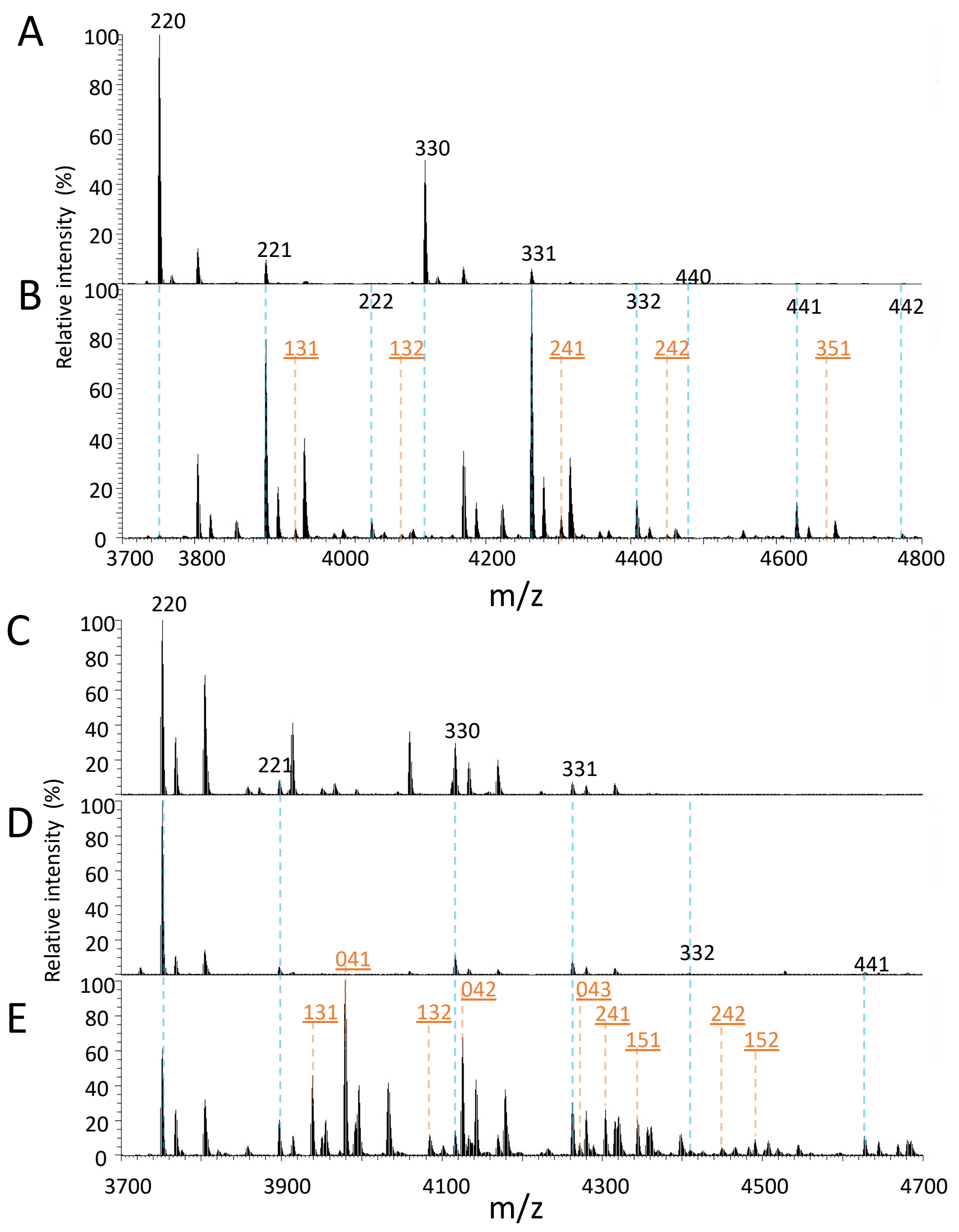

Supplemental Figure 4. Comparison of glycan composition on Asn-397 of CP. (A) Normal human plasma, (B) RMG-V cell line culture supernatant, and (C-E) ascites of CCC patients, specifically (C) nonfractionated, (D) nWFA-pass, and (E) nWFA-bound fractions. The numbers indicate signal ids (XYZ), with each digit presenting glycan compositions, which represent the numbers of $\operatorname{Hex}(X), \operatorname{HexNAc}(Y)$, and dHex (Z) monosaccharides, respectively, on the trimannosyl core (Hex3HexNAc2). Signal ids of putative LDN-containing glycan compositions are in orange and underlined. 


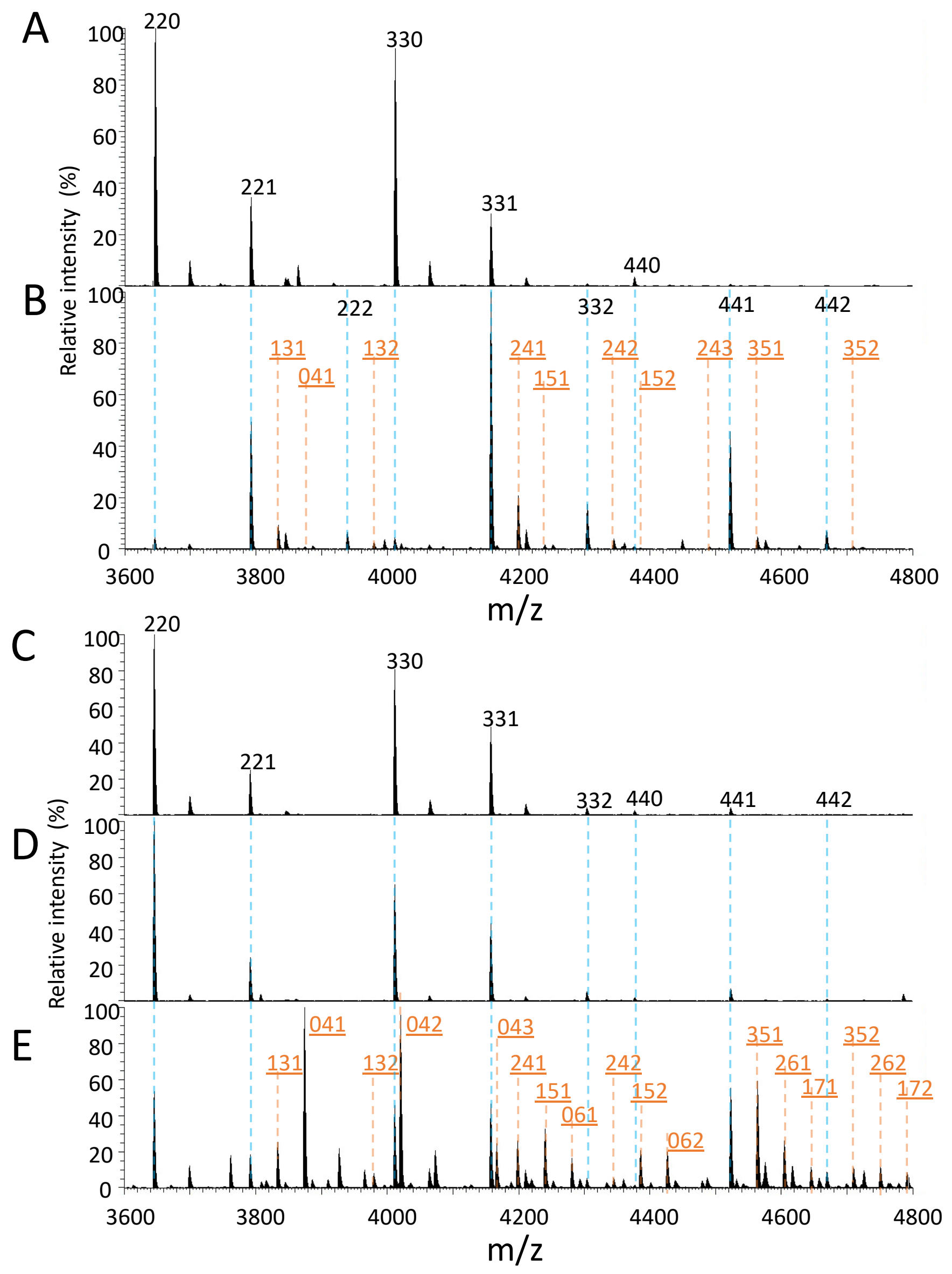

Supplemental Figure 5. Comparison of glycan composition on Asn-762 of CP. (A) Normal human plasma, (B) RMG-V cell line culture supernatant, and (C-E) ascites of CCC patients, specifically (C) nonfractionated, (D) nWFA-pass, and (E) nWFA-bound fractions. The numbers indicate signal ids (XYZ), with each digit presenting glycan compositions, which represent the numbers of $\operatorname{Hex}(X), \operatorname{HexNAc}(\mathrm{Y})$, and $\mathrm{dHex}(\mathrm{Z})$ monosaccharides, respectively, on the trimannosyl core (Hex3HexNAc2). Signal ids of putative LDN-containing glycan compositions are in orange and underlined. 
Supplemental Table 1. Mass spectrometry peak assignment of glycopeptides of CP

\begin{tabular}{|c|c|c|c|c|c|c|c|}
\hline \multirow[b]{2}{*}{ site } & \multirow[b]{2}{*}{ Signal id } & \multicolumn{3}{|c|}{ glycan composition } & \multirow[b]{2}{*}{ calculated $\mathrm{MH}+$} & \multicolumn{2}{|c|}{ Observed $\mathrm{MH}+$ (deconvoluted) } \\
\hline & & Hex & HexNAc & $\mathrm{dHex}$ & & $\begin{array}{l}\text { Normal human } \\
\text { serum }\end{array}$ & RMG-V-derived \\
\hline Asn138 & 220 & 5 & 4 & 0 & $3,515.422$ & $3,515.428$ & \\
\hline Asn138 & 221 & 5 & 4 & 1 & $3,661.480$ & $3,661.479$ & $3,661.480$ \\
\hline Asn138 & 131 & 4 & 5 & 1 & $3,702.507$ & & $3,702.496$ \\
\hline Asn138 & 041 & 3 & 6 & 1 & $3,743.534$ & & $3,743.519$ \\
\hline Asn138 & 222 & 5 & 4 & 2 & $3,807.538$ & & $3,807.530$ \\
\hline Asn138 & 132 & 4 & 5 & 2 & $3,848.565$ & & $3,848.549$ \\
\hline Asn138 & 330 & 6 & 5 & 0 & $3,880.555$ & $3,880.553$ & \\
\hline Asn138 & 042 & 3 & 6 & 2 & $3,889.591$ & & $3,889.572$ \\
\hline Asn138 & 331 & 6 & 5 & 1 & $4,026.613$ & $4,026.608$ & $4,026.610$ \\
\hline Asn138 & $\underline{241}$ & 5 & 6 & 1 & $4,067.639$ & & $4,067.627$ \\
\hline Asn138 & $\overline{332}$ & 6 & 5 & 2 & $4,172.670$ & $4,172.662$ & $4,172.662$ \\
\hline Asn138 & 440 & 7 & 6 & 0 & $4,245.687$ & $4,245.679$ & \\
\hline Asn138 & 441 & 7 & 6 & 1 & $4,391.745$ & $4,391.736$ & $4,391.743$ \\
\hline Asn138 & 351 & 6 & 7 & 1 & $4,432.771$ & & $4,432.765$ \\
\hline Asn138 & 442 & 7 & 6 & 2 & $4,537.803$ & $4,537.793$ & $4,537.795$ \\
\hline Asn138 & 550 & 8 & 7 & 0 & $4,610.819$ & $4,610.811$ & \\
\hline Asn138 & 551 & 8 & 7 & 1 & $4,756.877$ & $4,756.869$ & $4,756.864$ \\
\hline Asn358 & 220 & 5 & 4 & 0 & $3,262.371$ & $3,262.391$ & $3,262.369$ \\
\hline Asn358 & 221 & 5 & 4 & 1 & $3,408.429$ & $3,408.423$ & $3,408.450$ \\
\hline Asn358 & 131 & 4 & 5 & 1 & $3,449.456$ & & $3,449.450$ \\
\hline Asn358 & 222 & 5 & 4 & 2 & $3,554.487$ & & $3,554.483$ \\
\hline Asn358 & 132 & 4 & 5 & 2 & $3,595.514$ & & $3,595.499$ \\
\hline Asn358 & 330 & 6 & 5 & 0 & $3,627.504$ & $3,627.502$ & \\
\hline Asn358 & 331 & 6 & 5 & 1 & $3,773.561$ & $3,773.554$ & $3,773.570$ \\
\hline Asn358 & 241 & 5 & 6 & 1 & $3,814.588$ & & $3,814.576$ \\
\hline Asn358 & $\overline{332}$ & 6 & 5 & 2 & $3,919.619$ & & $3,919.610$ \\
\hline Asn358 & 242 & 5 & 6 & 2 & $3,960.646$ & & $3,960.630$ \\
\hline Asn358 & 440 & 7 & 6 & 0 & $3,992.636$ & $3,992.628$ & \\
\hline Asn358 & 152 & 4 & 7 & 2 & $4,001.673$ & & $4,001.657$ \\
\hline Asn358 & 441 & 7 & 6 & 1 & $4,138.694$ & & $4,138.695$ \\
\hline Asn358 & 351 & 6 & 7 & 1 & $4,179.720$ & & $4,179.712$ \\
\hline Asn358 & 442 & 7 & 6 & 2 & $4,284.752$ & & $4,284.763$ \\
\hline Asn397 & 220 & 5 & 4 & 0 & $3,749.580$ & $3,749.595$ & $3,749.568$ \\
\hline Asn397 & 221 & 5 & 4 & 1 & $3,895.638$ & $3,895.630$ & $3,895.652$ \\
\hline Asn397 & 131 & 4 & 5 & 1 & $3,936.665$ & & $3,936.647$ \\
\hline Asn397 & 222 & 5 & 4 & 2 & $4,041.696$ & & $4,041.690$ \\
\hline Asn397 & 132 & 4 & 5 & 2 & $4,082.723$ & & $4,082.701$ \\
\hline Asn397 & 330 & 6 & 5 & 0 & $4,114.713$ & $4,114.713$ & \\
\hline Asn397 & 331 & 6 & 5 & 1 & $4,260.771$ & $4,260.759$ & $4,240.770$ \\
\hline Asn397 & 241 & 5 & 6 & 1 & $4,301.797$ & & $4,301.783$ \\
\hline Asn397 & 332 & 6 & 5 & 2 & $4,406.828$ & $4,406.802$ & $4,406.822$ \\
\hline Asn397 & 242 & 5 & 6 & 2 & $4,447.855$ & & $4,447.845$ \\
\hline Asn397 & 440 & 7 & 6 & 0 & $4,479.845$ & $4,479.836$ & \\
\hline Asn397 & 441 & 7 & 6 & 1 & $4,625.903$ & $4,625.898$ & $4,625.898$ \\
\hline Asn397 & 442 & 7 & 6 & 2 & $4,771.961$ & & $4,771.950$ \\
\hline Asn762 & 220 & 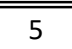 & 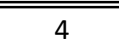 & 0 & $3,3,644.586$ & $3,3,644.581$ & \\
\hline Asn762 & 221 & 5 & 4 & 1 & $3,790.643$ & $3,790.644$ & $3,790.646$ \\
\hline Asn762 & 131 & 4 & 5 & 1 & $3,831.670$ & & $3,831.665$ \\
\hline Asn762 & 041 & 3 & 6 & 1 & $3,872.697$ & & $3,872.685$ \\
\hline Asn762 & 222 & 5 & 4 & 2 & $3,936.701$ & & $3,936.699$ \\
\hline Asn762 & 132 & 4 & 5 & 2 & $3,977.728$ & & $3,977.723$ \\
\hline Asn762 & 231 & 5 & 5 & 1 & $3,993.723$ & & $3,993.706$ \\
\hline Asn762 & 330 & 6 & 5 & 0 & $4,009.718$ & $4,009.719$ & \\
\hline Asn762 & 331 & 6 & 5 & 1 & $4,155.776$ & $4,155.775$ & $4,155.787$ \\
\hline Asn762 & 241 & 5 & 6 & 1 & $4,196.802$ & & $4,196.794$ \\
\hline Asn762 & $\overline{151}$ & 4 & 7 & 1 & $4,237.829$ & & $4,237.818$ \\
\hline Asn762 & 332 & 6 & 5 & 2 & $4,301.834$ & $4,301.823$ & $4,301.828$ \\
\hline Asn762 & 242 & 5 & 6 & 2 & $4,342.860$ & & $4,342.851$ \\
\hline Asn762 & 440 & 7 & 6 & 0 & $4,374.850$ & $4,374.841$ & \\
\hline Asn762 & 152 & 4 & 7 & 2 & $4,383.887$ & & $4,383.879$ \\
\hline Asn762 & 243 & 5 & 6 & 3 & $4,488.918$ & & $4,488.917$ \\
\hline Asn762 & 441 & 7 & 6 & 1 & $4,520.908$ & $4,520.902$ & $4,520.913$ \\
\hline Asn762 & 351 & 6 & 7 & 1 & $4,561.934$ & & $4,561.922$ \\
\hline Asn762 & 442 & 7 & 6 & 2 & $4,666.966$ & $4,666.961$ & $4,666.956$ \\
\hline Asn762 & 352 & 6 & 7 & 2 & $4,707.992$ & & $4,707.983$ \\
\hline
\end{tabular}

Peptide sequences used for mass calculation were follows. Asn138: EHEGAIYPDNTTDFQR (129-144), Asn358: AGLQAFFQVQECNK (S) (346-359), Asn397: ENLTAPGSDSAVFFEQGTTR (396-415), Asn762: ELHHLQEQNVSNAFLDK (754-770).

The signals presumed to be LDN-containing glycan were shaded, and the signal id were shown in orange in Figure 2 and Supplemental Figures S3-S5. In case of glycopeptides showed HexNAc(2) signal (m/z=407.166) on their MS2 spectra, their Signal ids were presented as underlined bold italic number. 
Supplemental Table 2. Mass spectrometry peak assignment of glycopeptides of CP from CCC patients' ascites. glycan composition

Observed $\mathrm{MH}+$ (deconvoluted)

\begin{tabular}{|c|c|c|c|c|c|c|c|c|}
\hline site & Signal id & Hex & HexNAc & $\mathrm{dHex}$ & calculated $\mathrm{MH}+$ & Whole ascites & WFA-pass & WFA-bound \\
\hline Asn138 & 220 & 5 & 4 & 0 & $3,515.422$ & $3,515.423$ & $3,515.430$ & $3,515.419$ \\
\hline Asn138 & 221 & 5 & 4 & 1 & $3,661.480$ & $3,661.473$ & $3,661.479$ & $3,661.479$ \\
\hline Asn138 & 131 & 4 & 5 & 1 & $3,702.507$ & & & $3,702.505$ \\
\hline Asn138 & 041 & 3 & 6 & 1 & $3,743.534$ & & & $3,743.531$ \\
\hline Asn138 & 222 & 5 & 4 & 2 & $3,807.538$ & & $3,807.532$ & \\
\hline Asn138 & 330 & 6 & 5 & 0 & $3,880.555$ & $3,880.550$ & $3,880.551$ & $3,880.558$ \\
\hline Asn138 & 042 & 3 & 6 & 2 & $3,889.591$ & & & $3,889.589$ \\
\hline Asn138 & 331 & 6 & 5 & 1 & $4,026.613$ & $4,026.605$ & $4,026.609$ & $4,026.609$ \\
\hline Asn138 & 043 & 3 & 6 & 3 & $4,035.649$ & & & $4,035.644$ \\
\hline Asn138 & 241 & 5 & 6 & 1 & $4,067.639$ & & & $4,067.632$ \\
\hline Asn138 & 151 & 4 & 7 & 1 & $4,108.666$ & & & $4,108.659$ \\
\hline Asn138 & 061 & 3 & 8 & 1 & $4,149.692$ & & & $4,149.682$ \\
\hline Asn138 & 332 & 6 & 5 & 2 & $4,172.670$ & $4,172.657$ & $4,172.661$ & \\
\hline Asn138 & 440 & 7 & 6 & 0 & $4,245.687$ & $4,245.681$ & $4,245.677$ & \\
\hline Asn138 & 152 & 4 & 7 & 2 & $4,254.724$ & & & $4,254.705$ \\
\hline Asn138 & 441 & 7 & 6 & 1 & $4,391.745$ & 4,391.737 & $4,391.740$ & $4,391.740$ \\
\hline Asn138 & 351 & 6 & 7 & 1 & $4,432.771$ & & & $4,432.764$ \\
\hline Asn138 & 261 & 5 & 8 & 1 & $4,473.798$ & & & $4,473.780$ \\
\hline Asn138 & $\overline{442}$ & 7 & 6 & 2 & $4,537.803$ & & $4,537.787$ & \\
\hline Asn358 & 2220 & $\overline{5}$ & 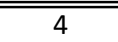 & $\overline{0} 0$ & "3,262.371 & "3,262.386 & & $3,3,262.368$ \\
\hline Asn358 & 221 & 5 & 4 & 1 & $3,408.429$ & $3,408.416$ & $3,408.427$ & $3,408.428$ \\
\hline Asn358 & 131 & 4 & 5 & 1 & $3,449.456$ & & & $3,449.454$ \\
\hline Asn358 & $\underline{041}$ & 3 & 6 & 1 & $3,490.482$ & & & $3,490.477$ \\
\hline Asn358 & $\overline{132}$ & 4 & 5 & 2 & $3,595.514$ & & & $3,595.511$ \\
\hline Asn358 & 330 & 6 & 5 & 0 & $3,627.504$ & $3,627.507$ & $3,627.503$ & \\
\hline Asn358 & 042 & 3 & 6 & 2 & $3,636.540$ & & & $3,636.536$ \\
\hline Asn358 & 331 & 6 & 5 & 1 & $3,773.561$ & $3,773.551$ & $3,773.557$ & $3,773.559$ \\
\hline Asn358 & 043 & 3 & 6 & 3 & $3,782.598$ & & & $3,782.591$ \\
\hline Asn358 & 241 & 5 & 6 & 1 & $3,814.588$ & & & $3,814.585$ \\
\hline Asn358 & 151 & 4 & 7 & 1 & $3,855.615$ & & & $3,855.609$ \\
\hline Asn397 & 220 & 5 & 4 & 0 & $3,749.580$ & $3,749.590$ & $3,749.586$ & $3,749.579$ \\
\hline Asn397 & 221 & 5 & 4 & 1 & $3,895.638$ & & $3,895.623$ & $3,895.640$ \\
\hline Asn397 & 131 & 4 & 5 & 1 & $3,936.665$ & & & $3,936.665$ \\
\hline Asn397 & $\underline{041}$ & 3 & 6 & 1 & $3,977.692$ & & & $3,977.686$ \\
\hline Asn397 & $\overline{132}$ & 4 & 5 & 2 & $4,082.723$ & & & $4,082.707$ \\
\hline Asn397 & 330 & 6 & 5 & 0 & $4,114.713$ & $4,114.714$ & $4,114.715$ & $4,114.708$ \\
\hline Asn397 & 042 & 3 & 6 & 2 & $4,123.749$ & & & $4,123.746$ \\
\hline Asn397 & 331 & 6 & 5 & 1 & $4,260.771$ & $4,260.770$ & $4,260.765$ & $4,260.767$ \\
\hline Asn397 & 043 & 3 & 6 & 3 & $4,269.807$ & & & $4,269.785$ \\
\hline Asn397 & 241 & 5 & 6 & 1 & $4,301.797$ & & & $4,301.792$ \\
\hline Asn397 & 151 & 4 & 7 & 1 & $4,342.824$ & & & $4,342.811$ \\
\hline Asn397 & 332 & 6 & 5 & 2 & $4,406.828$ & & $4,406.808$ & \\
\hline Asn397 & 242 & 5 & 6 & 2 & $4,447.855$ & & & $4,447.834$ \\
\hline Asn397 & 152 & 4 & 7 & 2 & $4,488.882$ & & & $4,488.860$ \\
\hline Asn397 & 441 & 7 & 6 & 1 & $4,625.903$ & & $4,625.899$ & $4,625.894$ \\
\hline Asn762 & 220 & 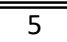 & 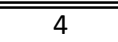 & 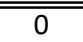 & "3,644.586 & "3,644.586 & "3,644.589 & $3,3,644.585$ \\
\hline Asn762 & 221 & 5 & 4 & 1 & $3,790.643$ & $3,790.635$ & $3,790.642$ & $3,790.641$ \\
\hline Asn762 & 131 & 4 & 5 & 1 & $3,831.670$ & & & $3,831.669$ \\
\hline Asn762 & 041 & 3 & 6 & 1 & $3,872.697$ & & & $3,872.694$ \\
\hline Asn762 & 132 & 4 & 5 & 2 & $3,977.728$ & & & $3,977.720$ \\
\hline Asn762 & 330 & 6 & 5 & 0 & $4,009.718$ & $4,009.716$ & $4,009.717$ & $4,009.714$ \\
\hline Asn762 & 042 & 3 & 6 & 2 & $4,018.755$ & & & $4,018.745$ \\
\hline Asn762 & 331 & 6 & 5 & 1 & $4,155.776$ & $4,155.770$ & $4,155.773$ & $4,155.770$ \\
\hline Asn762 & 043 & 3 & 6 & 3 & $4,164.812$ & & & $4,164.806$ \\
\hline Asn762 & 241 & 5 & 6 & 1 & $4,196.802$ & & & 4,196.798 \\
\hline Asn762 & 151 & 4 & 7 & 1 & $4,237.829$ & & & $4,237.820$ \\
\hline Asn762 & 061 & 3 & 8 & 1 & $4,278.855$ & & & $4,278.845$ \\
\hline Asn762 & 332 & 6 & 5 & 2 & $4,301.834$ & & $4,301.823$ & $4,301.825$ \\
\hline Asn762 & 242 & 5 & 6 & 2 & $4,342.860$ & & & $4,342.847$ \\
\hline Asn762 & 440 & 7 & 6 & 0 & $4,374.850$ & $4,374.836$ & $4,374.840$ & \\
\hline Asn762 & 152 & 4 & 7 & 2 & $4,383.887$ & & & $4,383.880$ \\
\hline Asn762 & 062 & 3 & 8 & 2 & $4,424.913$ & & & $4,424.903$ \\
\hline Asn762 & 441 & 7 & 6 & 1 & $4,520.908$ & $4,520.904$ & $4,520.897$ & $4,520.904$ \\
\hline Asn762 & 351 & 6 & 7 & 1 & $4,561.934$ & & & $4,561.929$ \\
\hline Asn762 & 261 & 5 & 8 & 1 & $4,602.961$ & & & $4,602.953$ \\
\hline Asn762 & 171 & 4 & 9 & 1 & $4,643.988$ & & & $4,643.967$ \\
\hline Asn762 & 442 & 7 & 6 & 2 & $4,666.966$ & $4,666.954$ & $4,666.956$ & $4,666.956$ \\
\hline Asn762 & 352 & 6 & 7 & 2 & $4,707.992$ & & & $4,707.973$ \\
\hline Asn762 & 262 & 5 & 8 & 2 & $4,749.019$ & & & $4,749.002$ \\
\hline Asn762 & 172 & 4 & 9 & 2 & $4,790.046$ & & & $4,790.031$ \\
\hline
\end{tabular}

Peptide sequences used for mass calculation were follows. Asn138: EHEGAIYPDNTTDFQR (129-144), Asn358: AGLQAFFQVQECNK (S) (346-359),

Asn397: ENLTAPGSDSAVFFEQGTTR (396-415), Asn762: ELHHLQEQNVSNAFLDK (754-770).

The signals presumed to be LDN-containing glycan were shaded, and the signal id were shown in orange in Figure 2 and Supplemental Figures S3-S5.

In case of glycopeptides showed HexNAc(2) signal ( $\mathrm{m} / \mathrm{z}=407.166$ ) on their MS2 spectra, their Signal ids were presented as underlined bold italic number. 


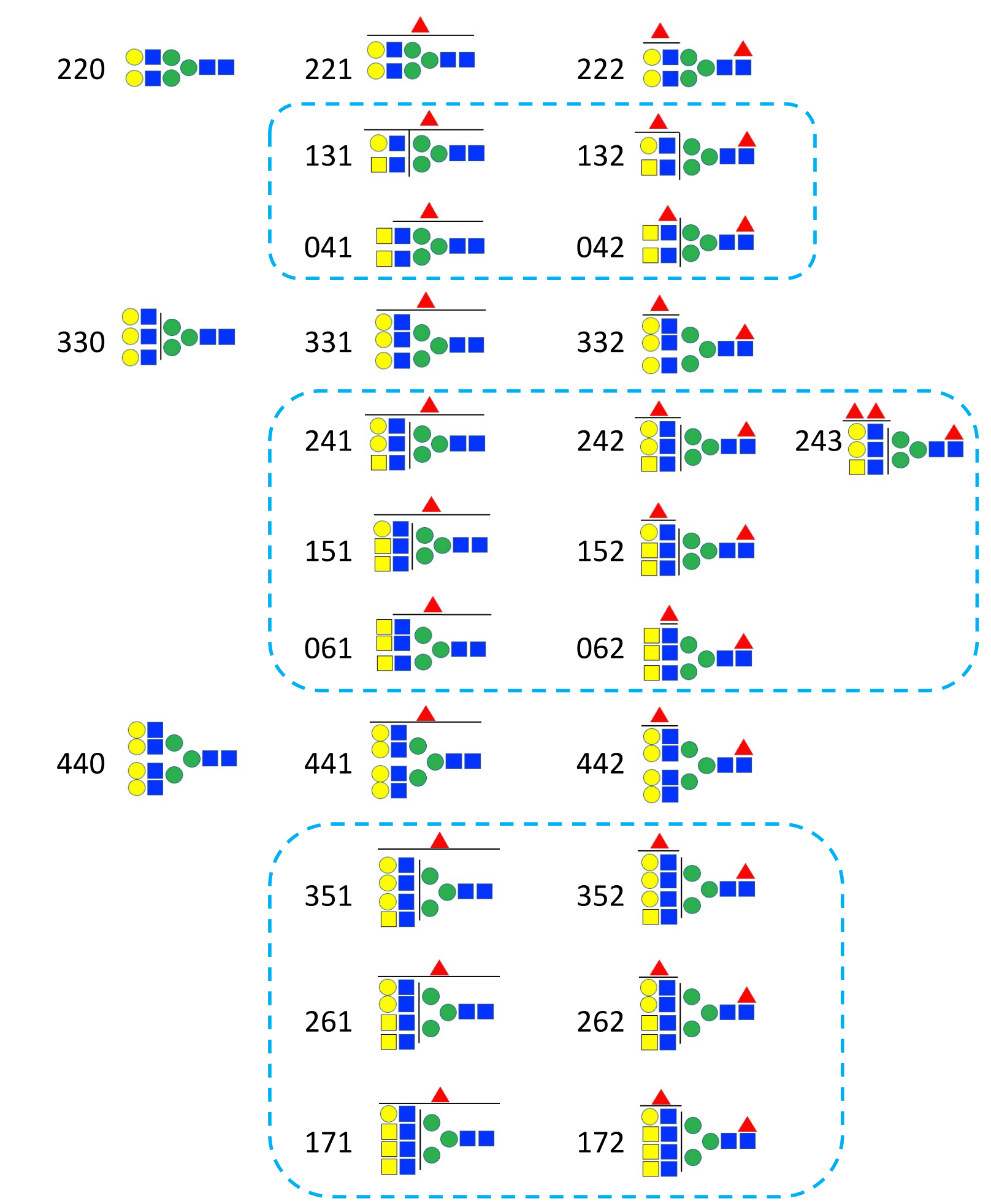

The compositions were detected in only WFA-bound fraction.

\begin{tabular}{|llll|}
\hline Gal $\bigcirc$ & GalNAc $\square$ & Fuc $\triangle$ & LDN $\square \square$ \\
Man $\bigcirc$ & GlcNAc & & LacNAc $\bigcirc \square$ \\
\hline
\end{tabular}

Supplemental Figure 6. Glycan id and its probable structure based on the binding affinity with WFA. Glycan structures are presented by Symbol Nomenclature for Glycans (SNFG). 


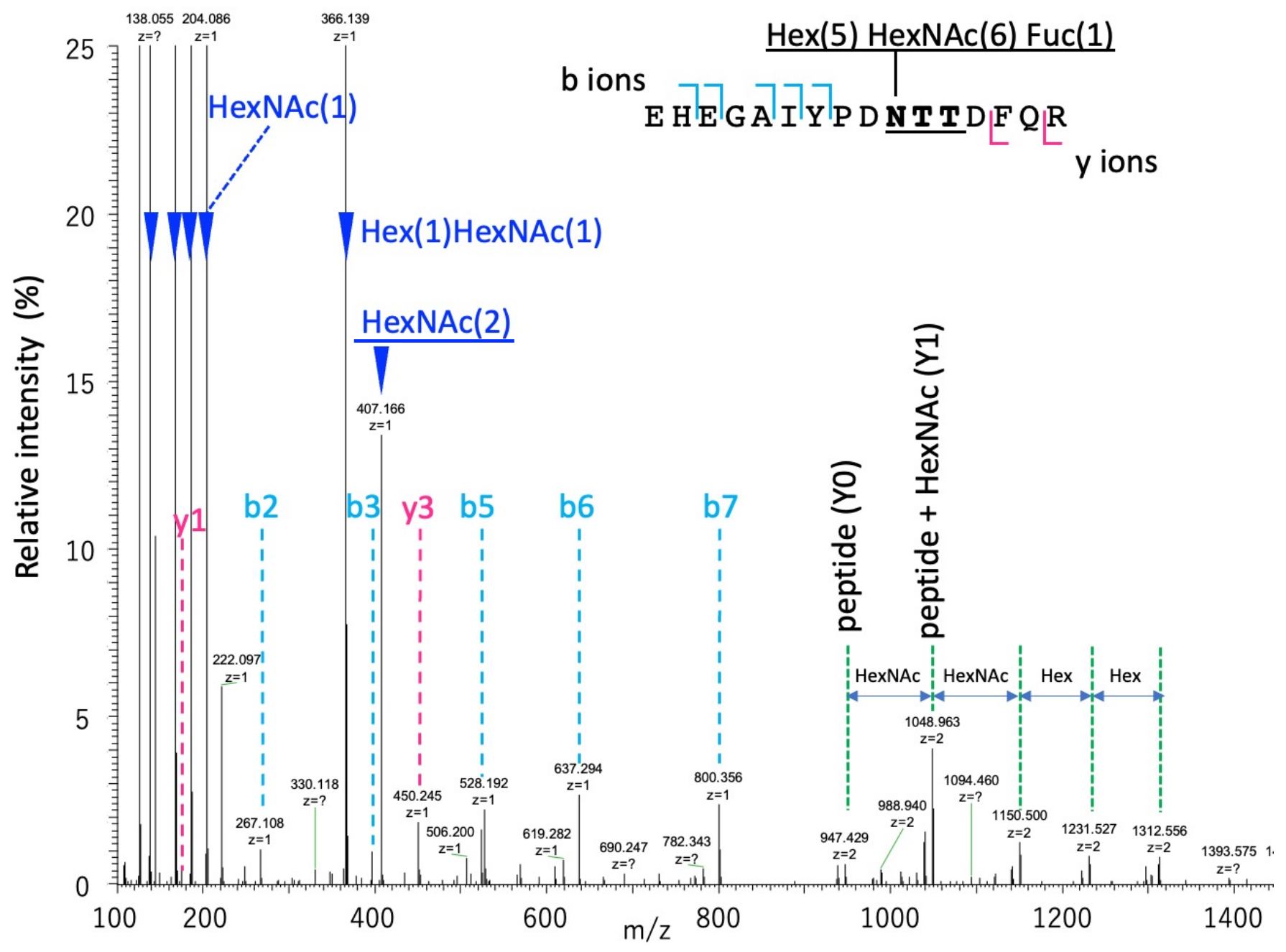

Supplemental Figure 7. HCD MS2 spectra of glycopeptides including Asn-138 of CP derived from culture supernatant of CCC cell line RMG-V. Signals shown with blue arrowheads were assigned as glycan diagnostic ions. Glycan fragment of $\mathrm{m} / \mathrm{z} 407.17$ indicates the presence of $\operatorname{HexNAc}(2)$ motif (underlined) suggesting GaINAc $\beta 1,4 G$ IcNAc (LDN) on the glycan. Pale blue and pink dotted lines present the $b$ and $y$ ions, respectively. Green dotted lines show signals of peptide and that having glycan portion. Glycan id 131 have both $\mathrm{H}(\mathrm{Hex})+\mathrm{HN}$ (HexNAc) and HN*2 fragments suggesting Gal $\beta 1,4$ GIcNAc (LacNAc) and LDN are seemed on the tri-mannosyl core. 
A

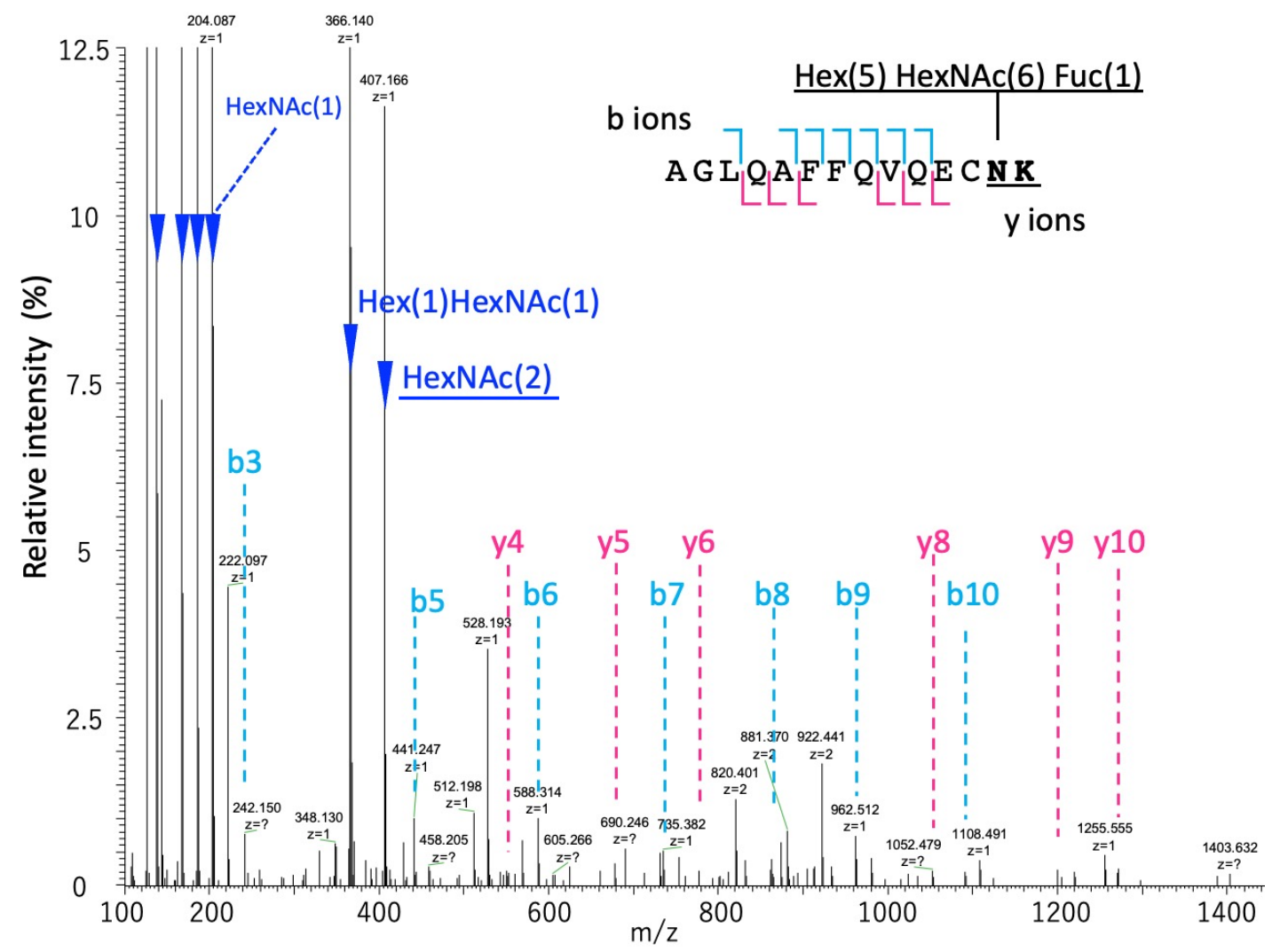

B

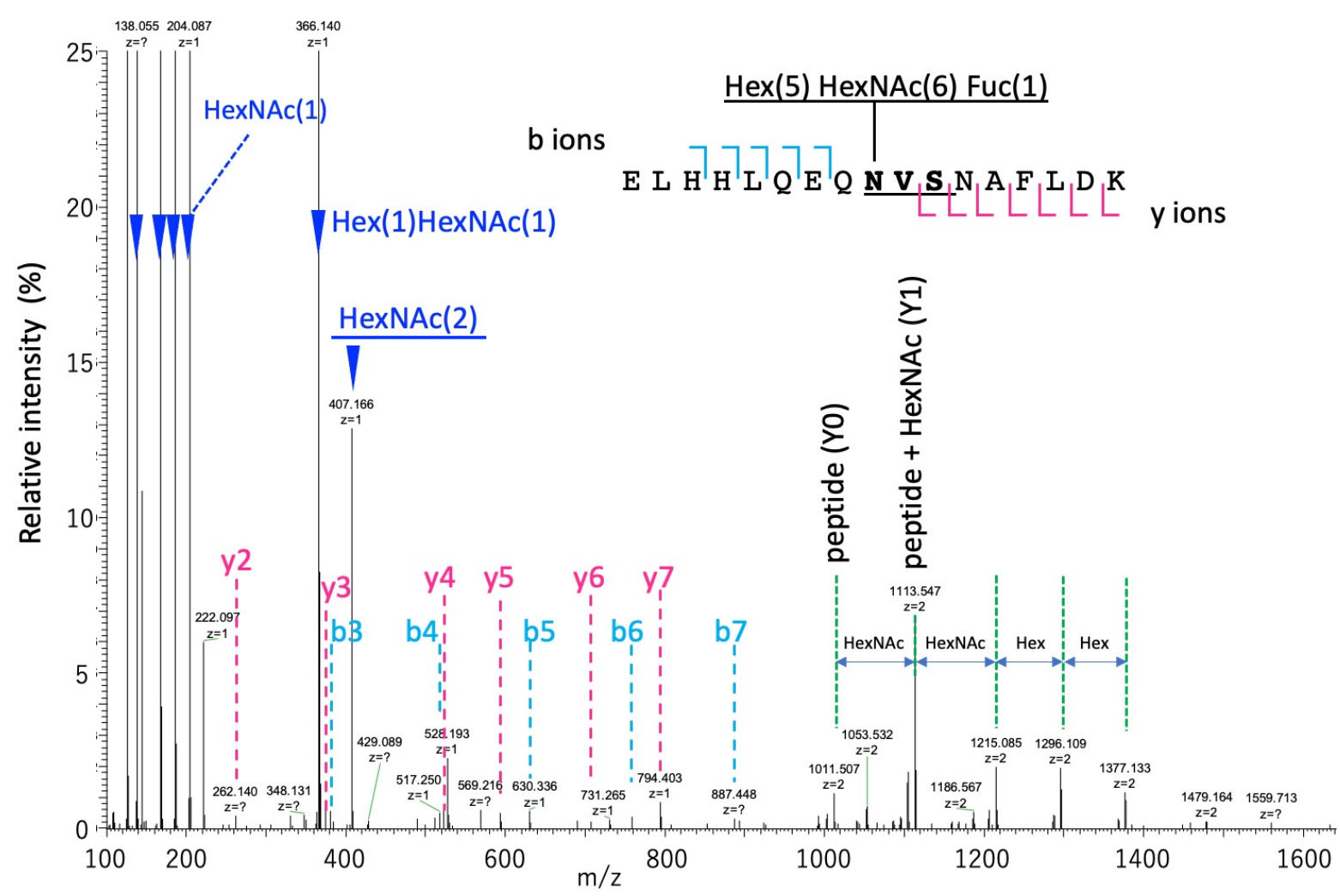

Supplemental Figure 8. HCD MS2 spectra of glycopeptide including A) Asn-358 and B) Asn-762 of CP derived from culture supernatant of CCC cell line RMG-V. Signals shown with blue arrowheads were assigned as glycan diagnostic ions. Glycan fragment of $\mathrm{m} / \mathrm{z} 407.17$ indicates the presence of $\operatorname{HexNAc}(2)$ motif (underlined) suggesting GalNAc $\beta 1,4$ GIcNAc (LDN) on the glycan. Pale blue and pink dotted lines present the $b$ and $y$ ions, respectively. Green dotted lines show signals of peptide and that having glycan portion. Glycan id 131 have both $\mathrm{H}(\mathrm{Hex})+\mathrm{HN}$ (HexNAc) and HN*2 fragments suggesting Gal $\beta 1,4 \mathrm{GlcNAc}$ ( $\operatorname{LacNAC}$ ) and LDN are seemed on the tri-mannosyl core. 


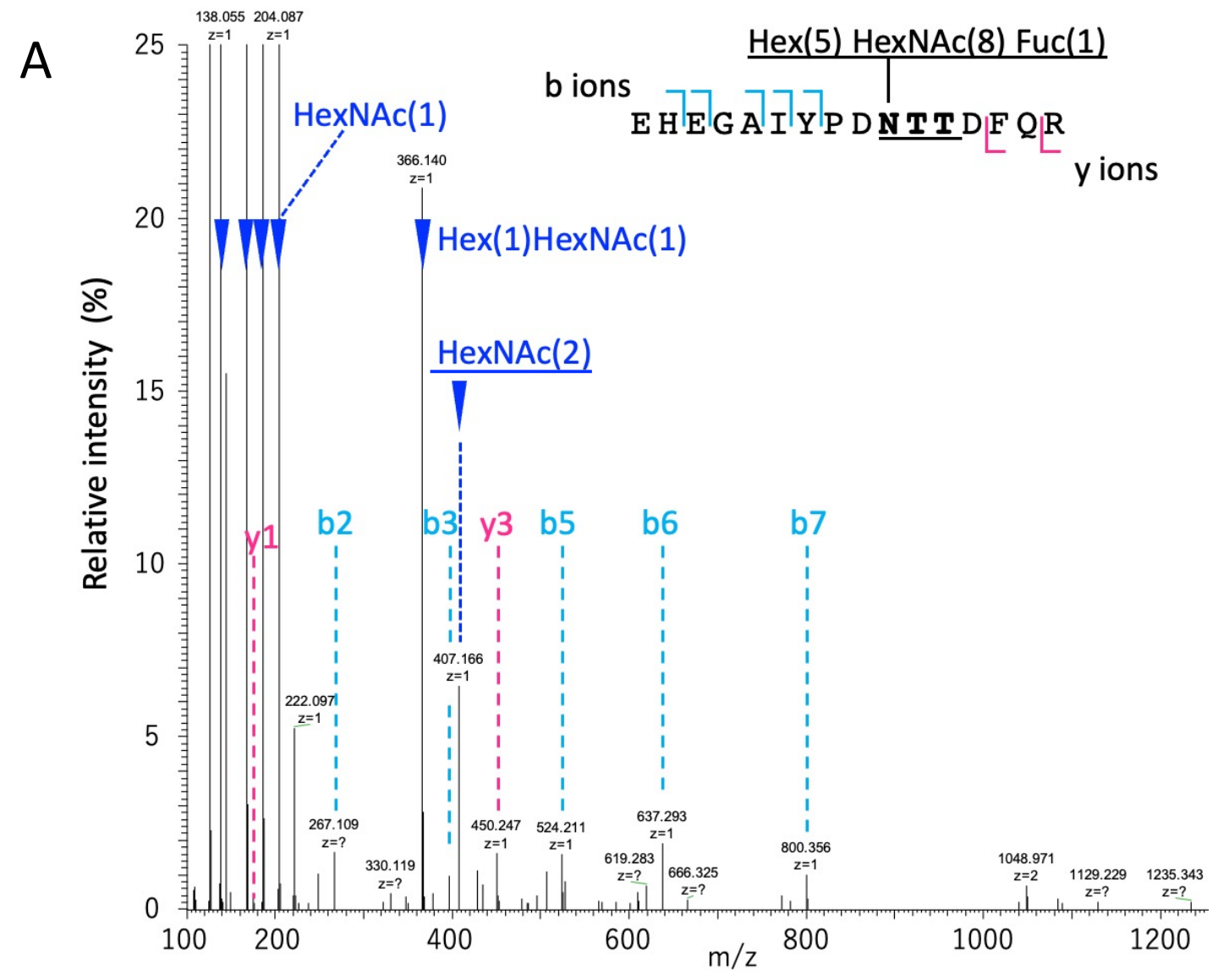

B

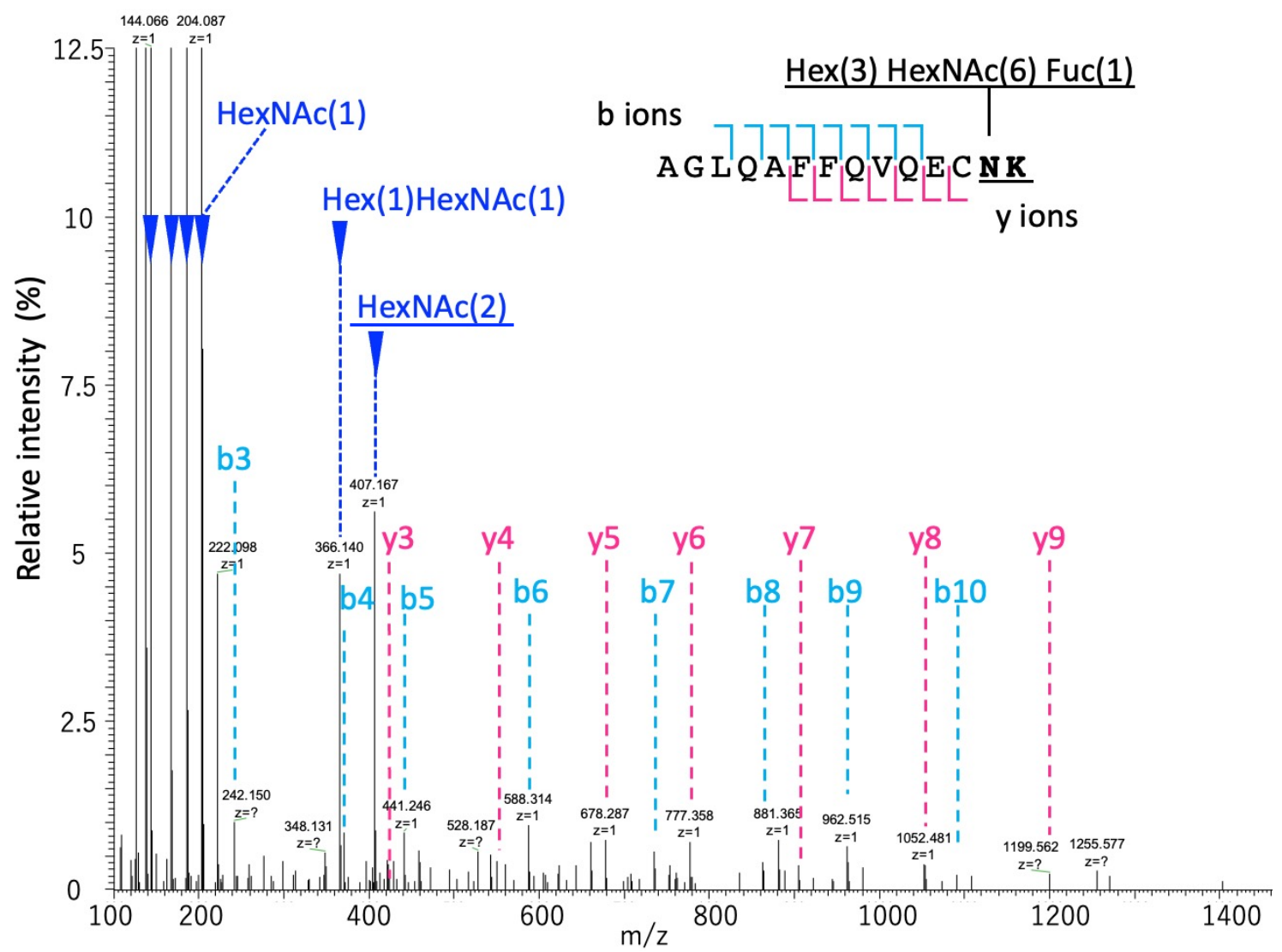

Supplemental Figure 9. HCD MS2 spectra of glycopeptide including A) Asn-138 and B) Asn-358 of CP derived from nWFA-bound fraction of CCC patients' ascites. Signals shown with blue arrowheads were assigned as glycan diagnostic ions. Glycan fragment of $\mathrm{m} / \mathrm{z} 407.17$ indicates the presence of $\mathrm{HexNAc}(2)$ motif (underlined) suggesting GaINAc $\beta 1,4$ GICNAc (LDN) on the glycan. Pale blue and pink dotted lines present the $b$ and $y$ ions, respectively. Green dotted lines show signals of peptide and that having glycan portion. Glycan id 131 have both $\mathrm{H}(\mathrm{Hex})+\mathrm{HN}$ (HexNAc) and HN*2 fragments suggesting Gal $\beta 1,4 \mathrm{GlcNAc}$ (LacNAc) and LDN are seemed on the tri-mannosyl core. 


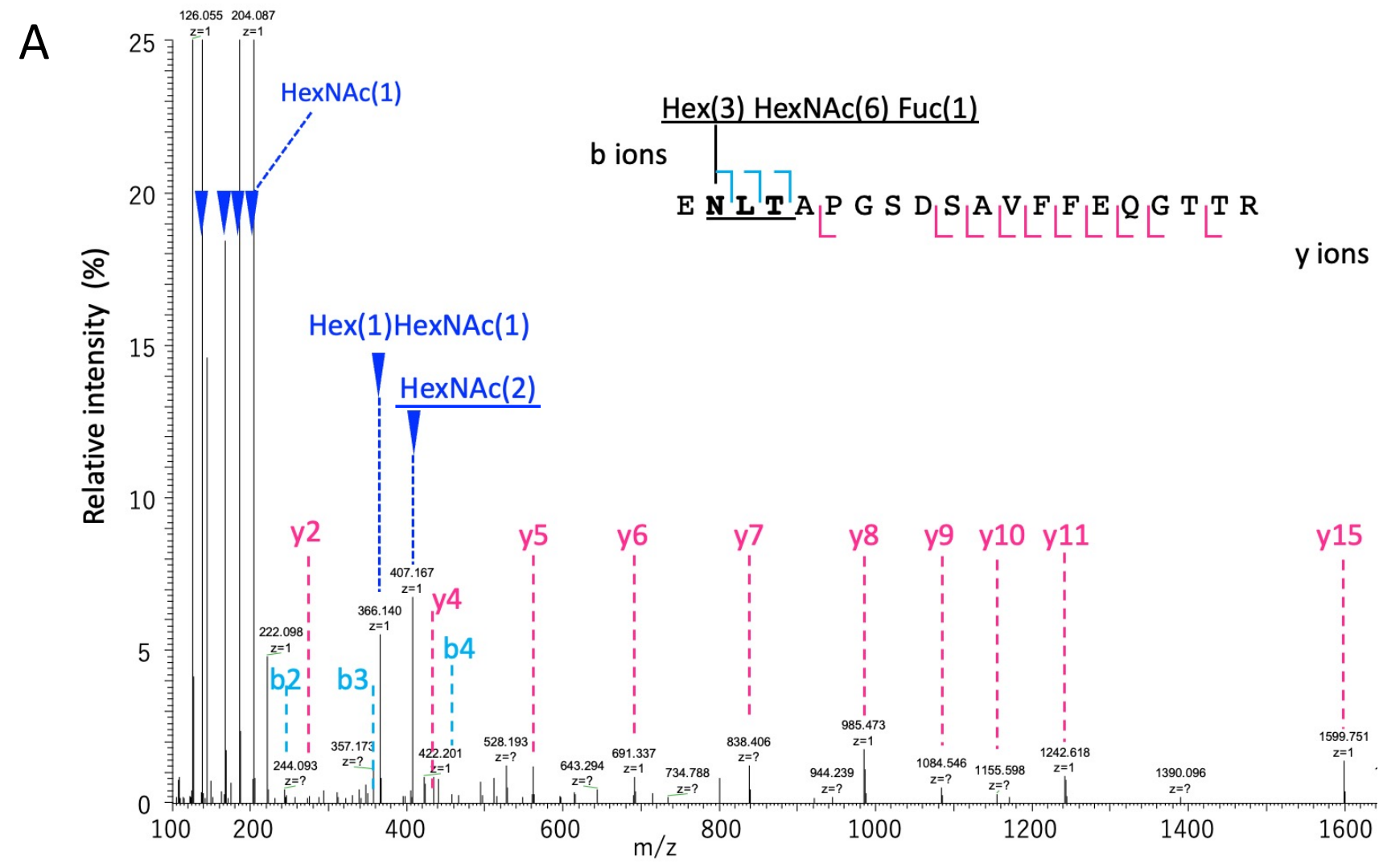

B

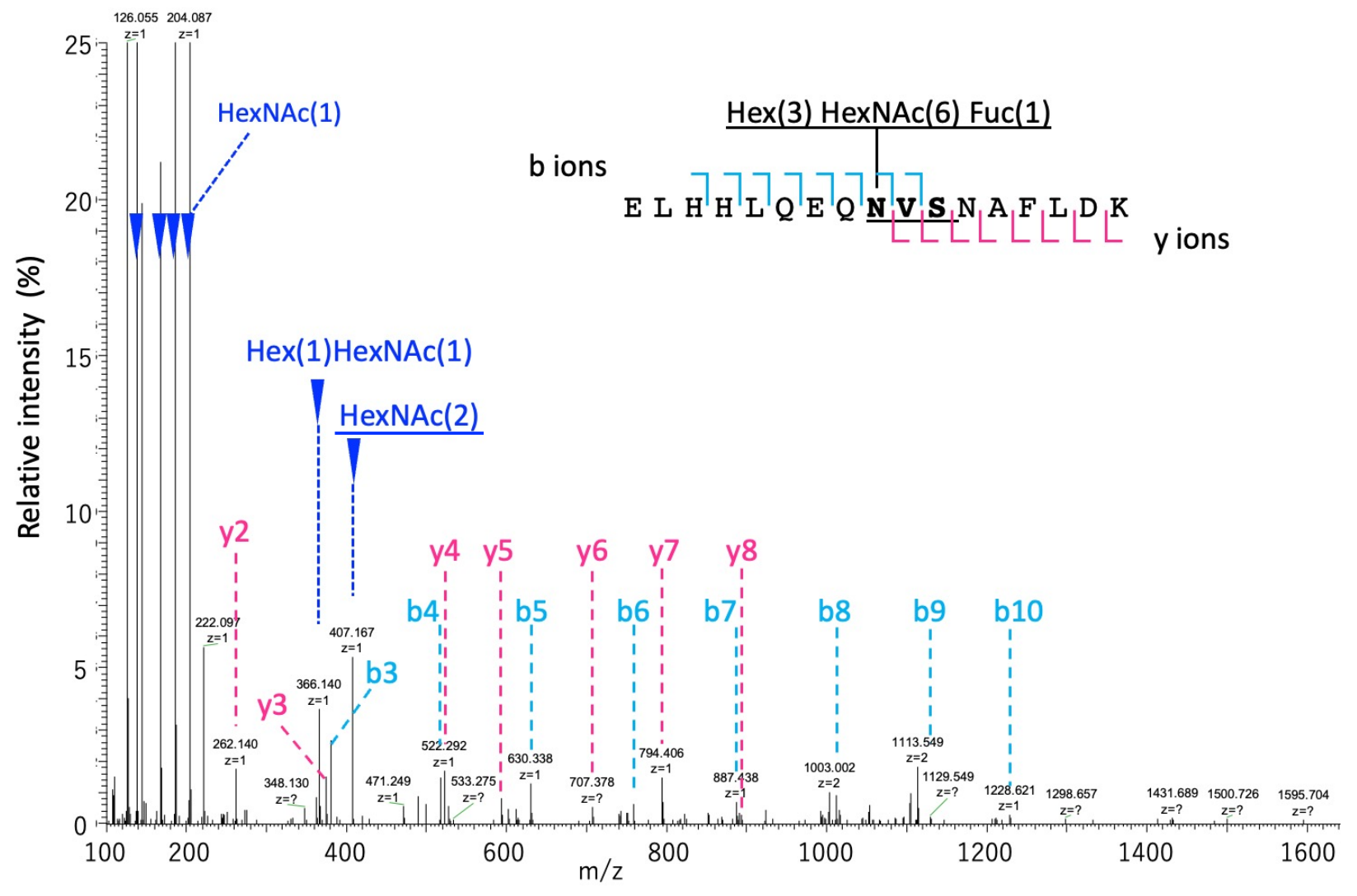

Supplemental Figure 10. HCD MS2 spectra of glycopeptide including A) Asn-397 and B) Asn-762 of CP derived from nWFA-bound fraction of CCC patients' ascites. Signals shown with blue arrowheads were assigned as glycan diagnostic ions. Glycan fragment of $\mathrm{m} / \mathrm{z} 407.17$ indicates the presence of $\operatorname{HexNAc}(2)$ motif (underlined) suggesting GalNAc $\beta 1,4$ GIcNAc (LDN) on the glycan. Pale blue and pink dotted lines present the $b$ and $y$ ions, respectively. Green dotted lines show signals of peptide and that having glycan portion. Glycan id 131 have both $\mathrm{H}(\mathrm{Hex})+\mathrm{HN}$ (HexNAc) and HN*2 fragments suggesting Gal $\beta 1,4 \mathrm{GIcNAc}$ (LacNAc) and LDN are seemed on the tri-mannosyl core. 
SPFS $\Delta S$

(counts/s)

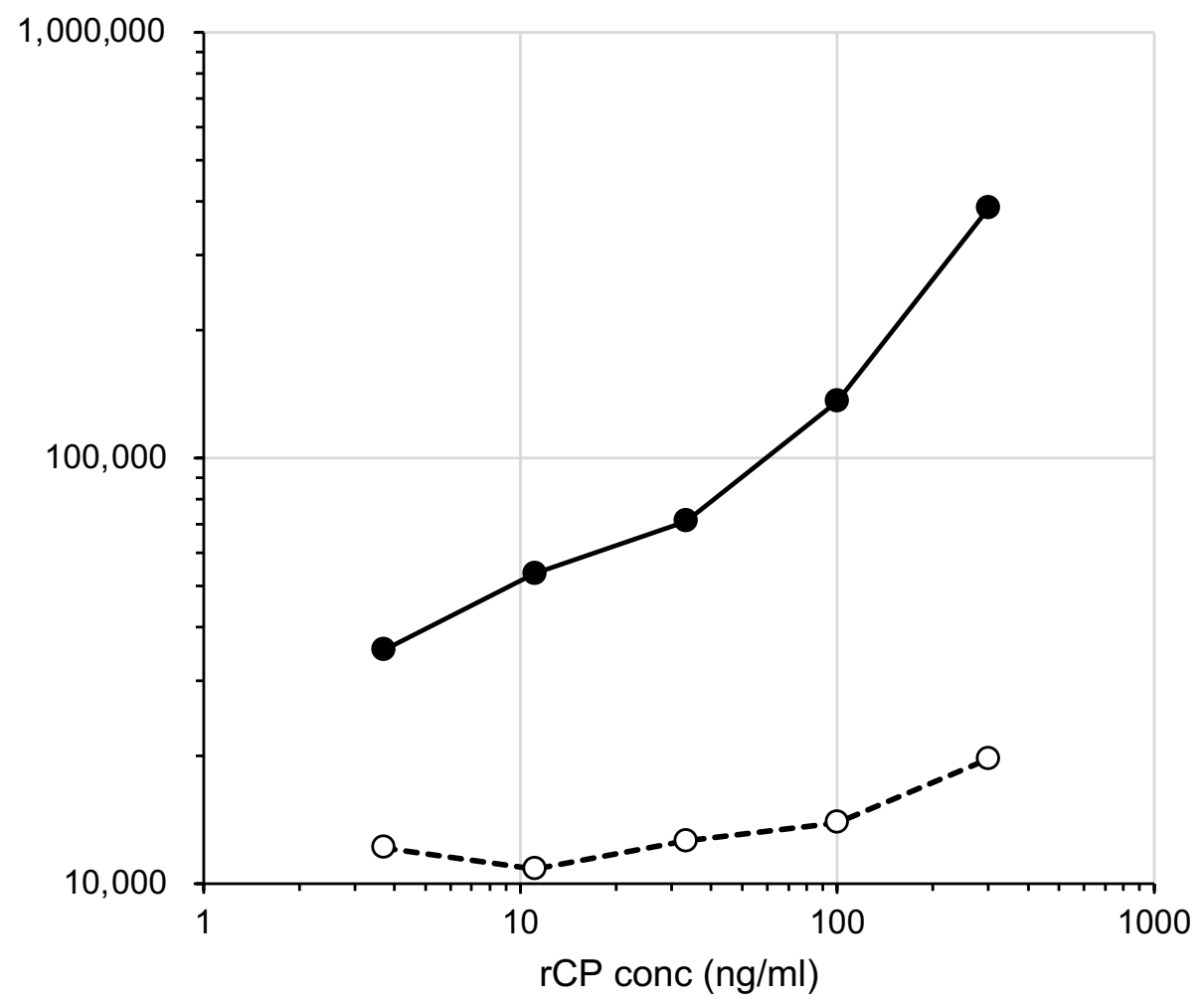

Supplemental Figure 11. Comparing SPFS signals of rWFA capturing and anti-CP capturing system with $10 \%$ NHS condition. Anti-CP antibody was immobilized on the solid phase and rWFA was labeled for detection (white circle with dotted line) or rWFA was immobilized on the solid phase and anti-CP was labeled for detection (black circle with solid line). A three-fold dilution series of rCP-added NHS was prepared and measured with SPFS system. This study was conducted with former prototype SPFS assay machine so that unit of signal is different from the main text due to its optical detector. 


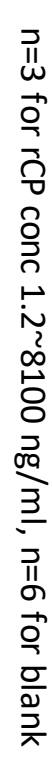

$\frac{C}{A}$

.

८

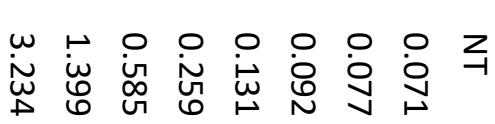

㞼

킁 ํำ

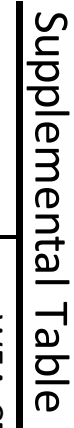

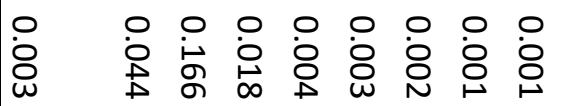

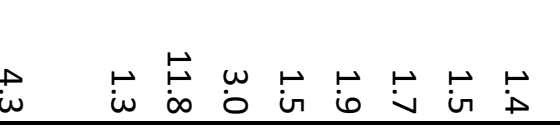

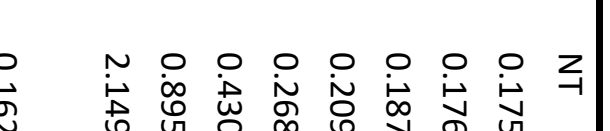

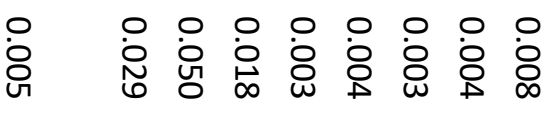

n

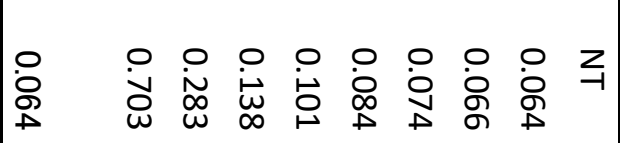

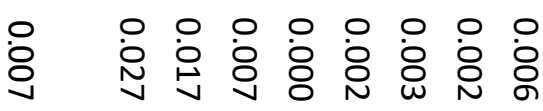

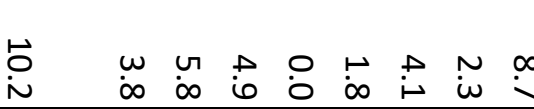

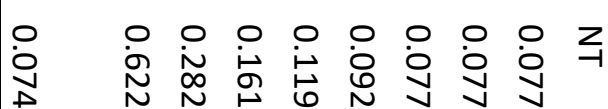

웅

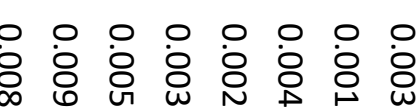

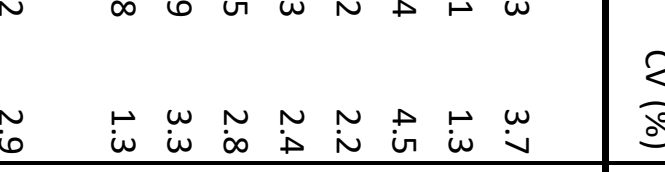

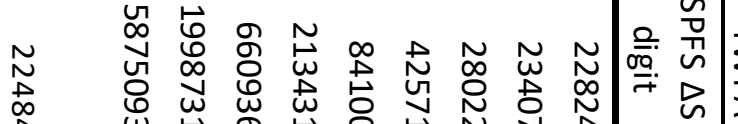

文 $\quad$ o

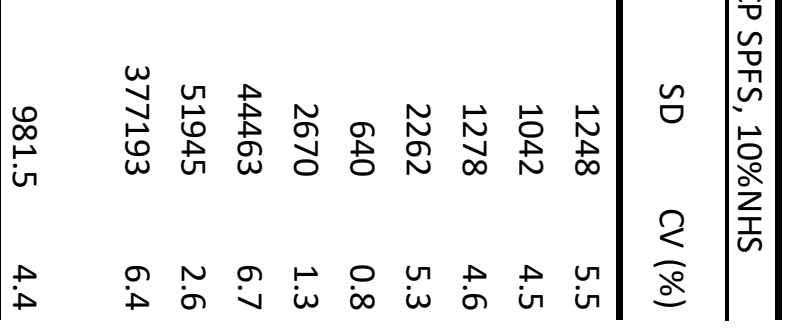


Supplemental Table 4. Measured value of serum samples

\begin{tabular}{|c|c|c|c|c|c|c|c|c|c|c|c|}
\hline Disease & Pathology & $\begin{array}{c}\text { Sample } \\
\text { No. }\end{array}$ & Stage & $\begin{array}{c}\text { rWFA-CP* } \\
\quad(\mathrm{ng} / \mathrm{mL})\end{array}$ & $\begin{array}{c}\mathrm{CA} 125^{* *} \\
(\mathrm{U} / \mathrm{ml})\end{array}$ & Disease & Pathology & $\begin{array}{c}\text { Sample } \\
\text { No. }\end{array}$ & Stage & $\begin{array}{r}\text { rWFA-CP* } \\
(\mathrm{ng} / \mathrm{mL})\end{array}$ & $\begin{array}{c}\mathrm{CA} 125^{* *} \\
(\mathrm{U} / \mathrm{ml})\end{array}$ \\
\hline \multirow[t]{43}{*}{$\overline{E O C}$} & \multirow[t]{15}{*}{ Serous } & Se1 & $\overline{\text { IIIC }}$ & 11.9 & 2625.3 & \multirow[t]{10}{*}{$\overline{\text { Non EOC }}$} & \multirow[t]{10}{*}{ Uterine cancer } & UtCa1 & I b & $<4.5$ & 6.6 \\
\hline & & $\mathrm{Se} 2$ & IIIC & $<4.5$ & 13.8 & & & UtCa2 & I b & $<4.5$ & 17.5 \\
\hline & & $\mathrm{Se} 3$ & IIIc & $<4.5$ & 5791.4 & & & UtCa3 & I C & $<4.5$ & 8.4 \\
\hline & & $\mathrm{Se} 4$ & IIIC & $<4.5$ & 76.2 & & & UtCa4 & I b & $<4.5$ & 11.0 \\
\hline & & Se5 & IIIc & $<4.5$ & 866.0 & & & UtCa5 & I b & $<4.5$ & 28.8 \\
\hline & & Se6 & $\mathrm{IV}$ & $<4.5$ & 1076.0 & & & UtCa6 & I C & $<4.5$ & 93.8 \\
\hline & & Se7 & IIIC & $<4.5$ & 1617.0 & & & UtCa7 & I a & $<4.5$ & 19.8 \\
\hline & & Se8 & III $b$ & $<4.5$ & 143.7 & & & UtCa8 & I b & $<4.5$ & 16.1 \\
\hline & & Se9 & IIIc & $<4.5$ & 2059.0 & & & UtCa9 & I a & $<4.5$ & 12.8 \\
\hline & & Se10 & IIIc & 21.0 & 1402.5 & & & UtCa10 & I b & $<4.5$ & 13.1 \\
\hline & & Se11 & IIIC & 46.1 & 1327.0 & \multirow[t]{20}{*}{ Benighn } & Endometrioma & Cyst1 & & $<4.5$ & 61.9 \\
\hline & & Se12 & III & 62.1 & 5728.0 & & & Cyst2 & & $<4.5$ & 75.0 \\
\hline & & Se13 & IV & 30.6 & 2513.0 & & & Cyst3 & & $<4.5$ & 56.8 \\
\hline & & Se14 & IIIC & $<4.5$ & 7146.0 & & & Cyst4 & & $<4.5$ & 25.0 \\
\hline & & Se15 & IV & $<4.5$ & 4323.0 & & & Cyst5 & & $<4.5$ & 110.9 \\
\hline & \multirow[t]{10}{*}{ Edometrio } & Em1 & IIIC & $<4.5$ & 1312.0 & & & Cyst6 & & $<4.5$ & 36.7 \\
\hline & & Em2 & II $\mathrm{b}$ & $<4.5$ & 1312.0 & & & Cyst7 & & 18.5 & 54.7 \\
\hline & & Em3 & I c(2) & $<4.5$ & 92.9 & & & Cyst8 & & $<4.5$ & 76.0 \\
\hline & & Em4 & I c(2) & $<4.5$ & 28.1 & & & Cyst9 & & $<4.5$ & 37.3 \\
\hline & & Em5 & I $\mathrm{c}$ & $<4.5$ & 56.3 & & & Cyst10 & & $<4.5$ & 31.7 \\
\hline & & Em6 & III & 67.6 & 236.0 & & Leiomyoma & My1 & & $<4.5$ & NT \\
\hline & & Em7 & I c(a) & $<4.5$ & 238.5 & & & My2 & & $<4.5$ & NT \\
\hline & & Em8 & I c (b) & $<4.5$ & 570.0 & & & My3 & & $<4.5$ & NT \\
\hline & & Em9 & I c (b) & $<4.5$ & 38.4 & & & My4 & & $<4.5$ & NT \\
\hline & & Em10 & I C & $<4.5$ & 2391.5 & & & My5 & & $<4.5$ & NT \\
\hline & \multirow[t]{10}{*}{ Clear cell } & CC1 & I c (b) & 641.5 & 588.0 & & & My6 & & $<4.5$ & NT \\
\hline & & CC2 & IIIb & $<4.5$ & 84.7 & & & My7 & & $<4.5$ & NT \\
\hline & & $\mathrm{CC} 3$ & I c & 5.1 & 93.9 & & & My8 & & $<4.5$ & NT \\
\hline & & CC4 & I a & 65.0 & 75.5 & & & My9 & & $<4.5$ & NT \\
\hline & & CC5 & I a & 765.1 & 114.0 & & & My10 & & $<4.5$ & NT \\
\hline & & CC6 & I c (b) & 125.0 & 33.3 & \multirow[t]{10}{*}{ Healthy } & & N1 & & $<4.5$ & 13.5 \\
\hline & & CC7 & I c (b) & 7.4 & 18.5 & & & N2 & & $<4.5$ & 8.7 \\
\hline & & $\mathrm{CC} 8$ & I c & 8.1 & 135.0 & & & N3 & & $<4.5$ & 12.9 \\
\hline & & $\mathrm{CCO}$ & I c(a) & 830.4 & 20.9 & & & N4 & & $<4.5$ & 6.2 \\
\hline & & CC10 & I c(2) & 37.7 & 20.6 & & & N5 & & $<4.5$ & 6.8 \\
\hline & \multirow[t]{8}{*}{ Musinous } & Mu1 & I c(b) & 4.7 & 5.0 & & & N6 & & $<4.5$ & 3.4 \\
\hline & & Mu2 & I a & $<4.5$ & 22.3 & & & N7 & & $<4.5$ & 3.7 \\
\hline & & Mu3 & I c(a) & 10.8 & 79.8 & & & N8 & & $<4.5$ & 6.5 \\
\hline & & Mu4 & I a & $<4.5$ & 10.9 & & & N9 & & $<4.5$ & 6.0 \\
\hline & & Mu5 & I c(2) & $<4.5$ & 773.2 & & & $\mathrm{~N} 10$ & & $<4.5$ & 3.9 \\
\hline & & Mu6 & I a & $<4.5$ & 23.6 & \multirow{3}{*}{\multicolumn{6}{|c|}{$\begin{array}{l}{ }^{*} \text { rWFA-CP Limit of detection }=4.5 \mathrm{ng} / \mathrm{ml} \\
{ }^{* *} \mathrm{CA} 125 \text { Limit of detection }=2 \mathrm{U} / \mathrm{ml} \text {, Cut } \\
\text { NT : not tested }\end{array}$}} \\
\hline & & Mu7 & I c (b) & $<4.5$ & 30.4 & & & & & & \\
\hline & & Mu8 & IIIc & $<4.5$ & 179.9 & & & & & & \\
\hline
\end{tabular}

